\title{
Enhanced Thermo-Optical Switching of Paraffin-Wax Composite Spots under Laser Heating
}

\author{
Asmaa Said, Abeer Salah * and Gamal Abdel Fattah \\ National Institute of Laser Enhanced Sciences, Cairo University, Cairo 12613, Egypt; \\ soom_asmaa_a@yahoo.com (A.S.); gfattah@niles.edu.eg (G.A.F.) \\ * Correspondence: abeersalah@niles.edu.eg; Tel.: +2-0-11-1917-8610
}

Academic Editor: Mady Elbahri

Received: 10 March 2017; Accepted: 8 May 2017; Published: 12 May 2017

\begin{abstract}
Thermo-optical switches are of particular significance in communications networks where increasingly high switching speeds are required. Phase change materials (PCMs), in particular those based on paraffin wax, provide wealth of exciting applications with unusual thermally-induced switching properties, only limited by paraffin's rather low thermal conductivity. In this paper, the use of different carbon fillers as thermal conductivity enhancers for paraffin has been investigated, and a novel structure based on spot of paraffin wax as a thermo-optic switch is presented. Thermo-optical switching parameters are enhanced with the addition of graphite and graphene, due to the extreme thermal conductivity of the carbon fillers. Differential Scanning Calorimetry (DSC) and Scanning electron microscope (SEM) are performed on paraffin wax composites, and specific heat capacities are calculated based on DSC measurements. Thermo-optical switching based on transmission is measured as a function of the host concentration under conventional electric heating and laser heating of paraffin-carbon fillers composites. Further enhancements in thermo-optical switching parameters are studied under Nd:YAG laser heating. This novel structure can be used in future networks with huge bandwidth requirements and electric noise free remote aerial laser switching applications.
\end{abstract}

Keywords: thermo-optical switching; paraffin wax; phase change materials; carbon fillers; graphene; graphite; composites

\section{Introduction}

One of the most significance advances in optical switching technology is Thermo-Optical Switching (TOS). TOS is a waveguide switching which is very attractive due to adequate speed for time critical applications and small size. The main principle of TOS is the variation of the refractive index of the material caused by temperature gradients [1,2].

Tailoring composite Phase Change Material (PCM) is of great interest mainly due to its interesting capabilities in solar energy storage, building energy savings and temperature control in electronic equipment to improve the overall system performance [3]. PCMs are linked to three energy storage methods: sensible heat, latent heat and chemical energy. Latent heat storage is an effective energy loading method due to high capacity and small temperature variation from storage to retrieval [4].

Paraffin wax is commonly used as a phase change material, exhibiting high latent heat thermal energy storage and low temperature variation, although this material suffers from low thermal conductivity $\sim 0.24 \mathrm{~W} / \mathrm{m} \cdot \mathrm{K}[3-5]$. Graphene and graphite are recently used to enhance the low thermal conductivity of paraffin wax [6-9], and to accelerate melting and solidification heat transfer rates [10-12]. Graphite features excellent physical properties such as high electrical and thermal conductivities, high heat of fusion and thermal stability. Graphene has shown remarkable applicability in diverse areas as catalysis, sensors, biomedicine, composites, and energy devices [13-16]. 
Several high thermal conductive fillers have been reported to improve the thermal conductivity of PCMs. In this sense, various approaches have been recently reported: graphite foam [17]; compressed expanded natural graphite to improve Wood's alloy heat transfer [18]; exfoliated graphite nanoplatelets to form paraffin composite phase change material [3]; adding various nano-additives to liquid paraffin of various sizes and shapes $[16,19,20]$; and adding various nanofillers such as long and short multi-walled carbon nanotubes, carbon nanofibers, graphene nanoplatelets [21] and graphene-nickel/n carboxylic acids composites [22], among many others. Other interesting routes are based in 2D ordered elements such as carbon and boron nitride, which were used by Fang et al. [23] to be incorporated in PCM with significance performance.

In this work, we address a simple thermo-optical switching technique based on the transmission change under different heating conditions by means of Nd:YAG laser as a heating source. TOS arise from the following concepts: the wax has two states, translucent (OFF) and transparent (ON), below and above the melting temperature, respectively. If a powerful heating pulse (laser pulses and electric hot filament) affects a small spot of paraffin wax, the state of the wax changes from the solid to liquid phase (OFF/ON) after certain switching time. Reports on the use of laser heating in different fields confirm the applicability of this technique, such as accelerating thermo-mechanical fatigue of metallization [24], tailor mechanical properties of steel tube [25], inducing phase change in vanadium dioxide crystals [26], and bending titanium alloy sheets [27].

This research reports on the preparation, characterization and examination of the thermo-optical switching performance of paraffin-wax spot composites under conventional electric heating and laser heating. We extend a previous work for the TOS transmission of light through paraffin wax under electric heating of $1.3 \mathrm{mg}$ of wax [28,29]. Here, mille-sized spots are studied to gain a small quantity of heat in a short time undergoing to the melting phase. Hence, thermo-optical switching in spot morphology is expected to be faster. The switching temperature and the switching time are important factors for the switching performance. Thermo-optical switching has a large optical bandwidth, small physical dimensions, large fabrication tolerances, and good performances. In addition, a laser pulse is used for remote aerial switching. The switching efficiency is enhanced in the studied composites, which makes the design applicable in aerial communications.

\section{Materials and Methods}

\subsection{Materials and Sample Preparation}

The chemical preparations of the composites require the following:

- Paraffin wax from DIFCO laboratories (Detroit, MI, USA) was used as a PCM; its formula $\mathrm{C}_{n} \mathrm{H}_{2 n+2}$ where $n=26$. Graphite $(\mathrm{G})$ and graphene $(\mathrm{Gn})$ were used to enhance the thermal properties of paraffin wax. Paraffin wax, graphite and graphene have different thermal properties.

- Graphite was obtained from Johnson Matthey Catalog Company (WAR HILL, MA, USA) as a commercial graphite rod with diameter $6.15 \mathrm{~mm}$ and length $150 \mathrm{~mm}$, and purity $99.9995 \%$. Graphite with micron size was used in our work. A small amount of graphite powder (from) was ground from the graphite rod to prepare different concentration of graphite.

- Graphene was synthesized in Nanotech Egypt for photoelectronics. The powder graphene used in our work had black color and nano size. The synthesis of graphene was achieved by chemical reduction of graphene oxide [30,31].

Grinding the graphite or the graphene is done using agate mortar. Then, the molten wax was added to the ground particles. In the case of graphite-paraffin wax, $2.5 \mathrm{~mL}$ toluene was added into the molten paraffin wax to get homogenous distribution through the paraffin matrix, while no solvent was added in the case of grapheme-wax composite. Mixtures were stirred for $2 \mathrm{~h}$ under heating at $70^{\circ} \mathrm{C}$. Two series were prepared of paraffin wax composites: the first one is for graphite-paraffin composites dispersed in toluene with percentages $0 \%, 0.007 \%, 0.03 \%, 0.07 \%, 0.3 \%, 0.7 \%, 3 \%$ and $7 \%$, and the 
second series is for grapheme-paraffin composite with percentages $0 \%, 0.001 \%, 0.005 \%, 0.007 \%, 0.03 \%$, $0.07 \%, 0.3 \%$ and $0.7 \%$. Inject a spot of paraffin wax composites $(1.3 \mathrm{mg})$ in the center of capillary tube with inner diameter $1 \mathrm{~mm}$ in order to study the thermo optical switching properties through optic fiber light transmission.

\subsection{Thermo-Optical Switching through Optical Fiber Transmission Setup}

Thermo-optical switching under electrical heating is measured for the composites inside a glass capillary tube, while, in the case thermo-optical switching under laser heating, a copper capillary tube is used. As mentioned before, Paraffin wax composites were melted in a pot on a heating plate. Then, the molten composite spot is injected into the center of the capillary tube.

The setup components are listed below as follows:

- A laser beam from laser Max INC. (Rochester, NY, USA), output power $\leq 4.25 \mathrm{mw}$ and wavelength $677 \mathrm{~nm}$.

- Fused silica optical fiber with core diameter $200 \mu \mathrm{m}$, cladding diameter $250 \mu \mathrm{m}$ and jacket diameter $1 \mathrm{~mm}$.

- Glass capillary tube is from Micro-Hematocrites, with inner diameter 1.1-1.2 mm. The capillary tube is surrounded by helical heater with 20 watt power.

- Copper capillary tube is fabricated from copper sheet with inner diameter $1 \mathrm{~mm}$.

- Thermocouple with $\mathrm{K}$ type, its accuracy \pm 1 of reading and its resolution $1^{\circ} \mathrm{C}$; the thermocouple records temperature during heating and cooling in the temperature range $20-90{ }^{\circ} \mathrm{C}$.

- $\quad$ Power meter with model number THORLABS S142C: Its spectral range varies from 350 to $1100 \mathrm{~nm}$ and the head of power meter is Si detector.

- The Nd:YAG laser, model No. SL-10 (Continuum, Santa Clara, CA, USA), with energy pulse $110 \mathrm{~mJ}, 1064 \mathrm{~nm}$ wavelength, $10 \mathrm{~Hz}$ frequency reputation rate and $6 \mathrm{~ns}$ pulse duration.

A laser beam is directed to the sample in the capillary tube through optical fiber (Figure 1), and the transmission intensities were measured via optical power meter. The sample is under heating using laser pulses, where, for electrical heating, a helical heater is used. Using a copper sheet as a capillary tube is mandatory to bear high power of pulsed laser, as the glass capillary tube broke under exposure to laser pulses. The transmission is recorded as a function of time and temperature under heating the samples.

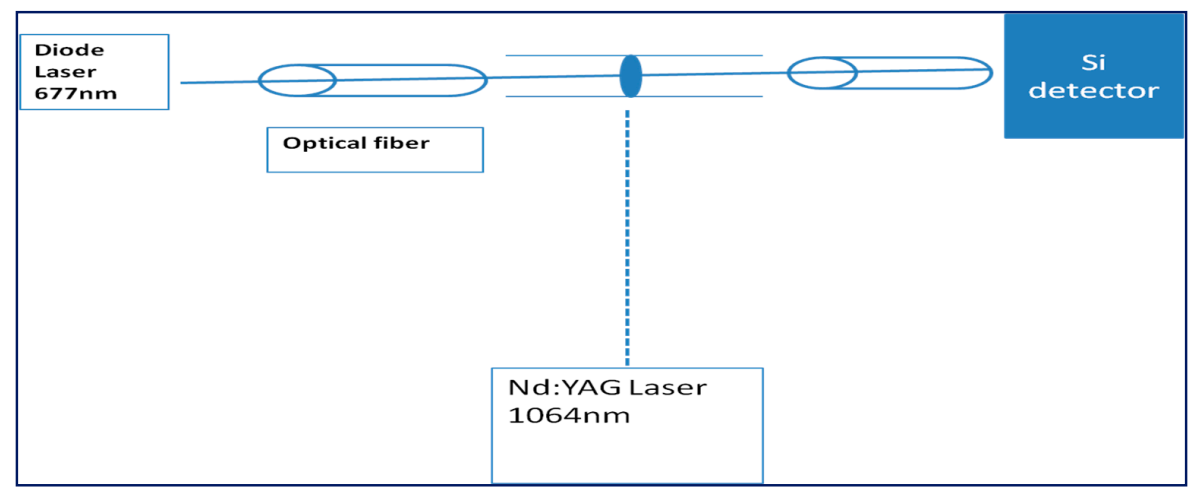

Figure 1. Thermo-optical switching setup using Nd:YAG as a heating source. The sample is under heating using Nd:YAG laser pulses: a laser beam $677 \mathrm{~nm}$ is directed to the sample in the capillary tube through optical fiber, and the transmission intensities were measured via optical power meter as a function of time.

Thermal properties such as melting temperature, solidifying temperature, latent heat capacity, heat gained, and heat lost of paraffin wax composites were measured by differential Scanning Caliormeter 
(DSC-50, Shimadzu, Coulombia, MA, USA). The thermal properties of paraffin wax composites were measured during cooling under nitrogen atmosphere. DSC measurements were performed at $10{ }^{\circ} \mathrm{C} / \mathrm{min}$ heating and cooling rates for temperature range from room temperature to $90^{\circ} \mathrm{C}$. Scanning electron microscopy (SEM) was carried out using QUANTA FEG250 SEM instrument (FEI, Hillsbor, OR, USA) to determine the particle size.

\section{Results and Discussion}

\subsection{Morphology}

Scanning electron microscopy (SEM) confirms further homogenity of the paraffin composite samples (Figure 2). The average particle size is about 6.2 and $8.4 \mu \mathrm{m}$ for graphite and graphene, respectively, in paraffin composites.

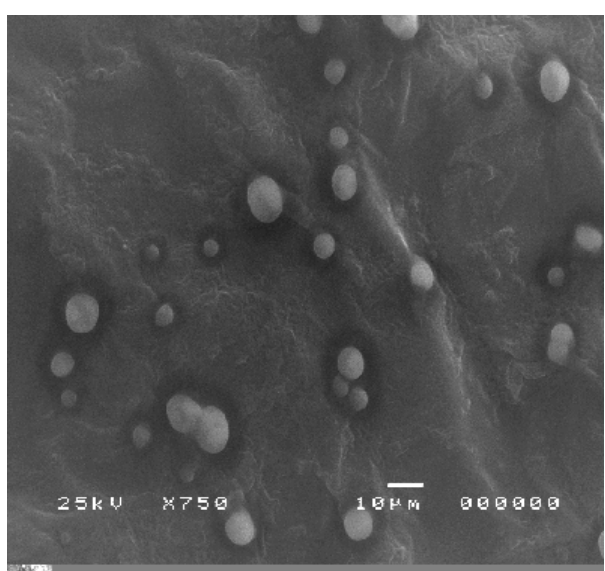

(a) G/Wax

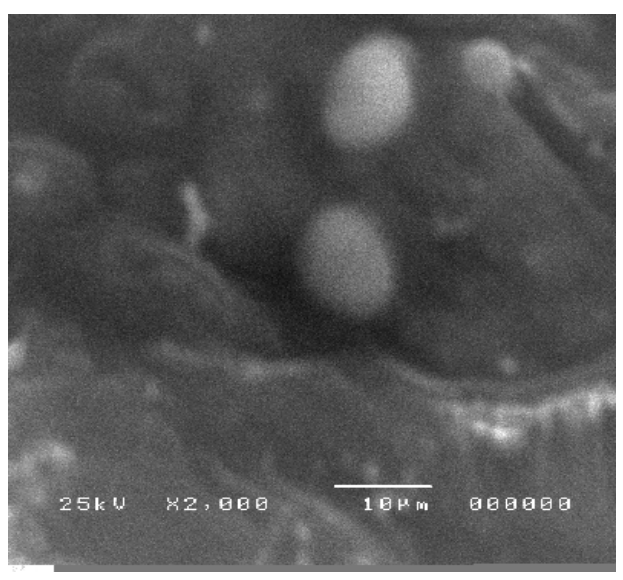

(b) $\mathrm{Gn} / \mathrm{Wax}$

Figure 2. Scanning Election microscopy of paraffin wax hosting: (a) graphite dispersed in toluene; and (b) graphene.

\subsection{DSC of Paraffin Wax Composites}

The influence of graphite and graphene addition on the thermal properties including the melting temperatures and latent heat of fusion were analyzed from the DSC measurement. The DSC of pure paraffin wax is a reference to evaluate the thermal properties changes depending on the paraffin graphite composite ratio.

It can be seen from DSC curves (Figure 3) that the heating curves represent the absorbed energy by the material in endothermic phase transition while cooling curves represent the expelled energy by the material in exothermic phase transition. For pure paraffin wax, there are two endothermic peaks in the DSC curves (Figure 3a): the main peak corresponds to solid-liquid phase change $T_{2}$ of the paraffin at about $52.54{ }^{\circ} \mathrm{C}$ and the minor peak represents solid-solid phase transition $\mathrm{T}_{1}$ of the paraffin wax at about $36.19^{\circ} \mathrm{C}$. These peaks match the pure paraffin wax peaks in other reports $[4,32]$. There are also two endothermic peaks for paraffin wax graphite composites: the solid-liquid peak $\mathrm{T}_{2}$ fluctuates around $52{ }^{\circ} \mathrm{C}$, while the solid-solid $\mathrm{T}_{1}$ transition peak is altered from 36 to $34^{\circ} \mathrm{C}$. The thermal properties of the paraffin wax-graphite composites are very close that of pure paraffin wax. This is because there are no chemical interactions between paraffin wax and graphite through preparation of the samples. Zhang et al. $[33,34]$ observed the same behavior for expanded graphite-paraffin wax composite.

For DSC of Paraffin wax/Gn (Figure $3 b$ ), during the heating phase, $T_{1}$ is decreased from 42 to $35{ }^{\circ} \mathrm{C}$ and $\mathrm{T}_{2}$ is decreased from 59 to $52{ }^{\circ} \mathrm{C}$ as the concentration of the graphene increases. In the cooling phase, there is a noticeable decrease from 53 to $48{ }^{\circ} \mathrm{C}$ and from 40 to $32{ }^{\circ} \mathrm{C}$, respectively, as the concentration of the graphene increases. There may be chemical reactions between the graphene 
and paraffin wax, which needs further measurements, such as X-ray diffraction (XRD), which will be completed in further work.

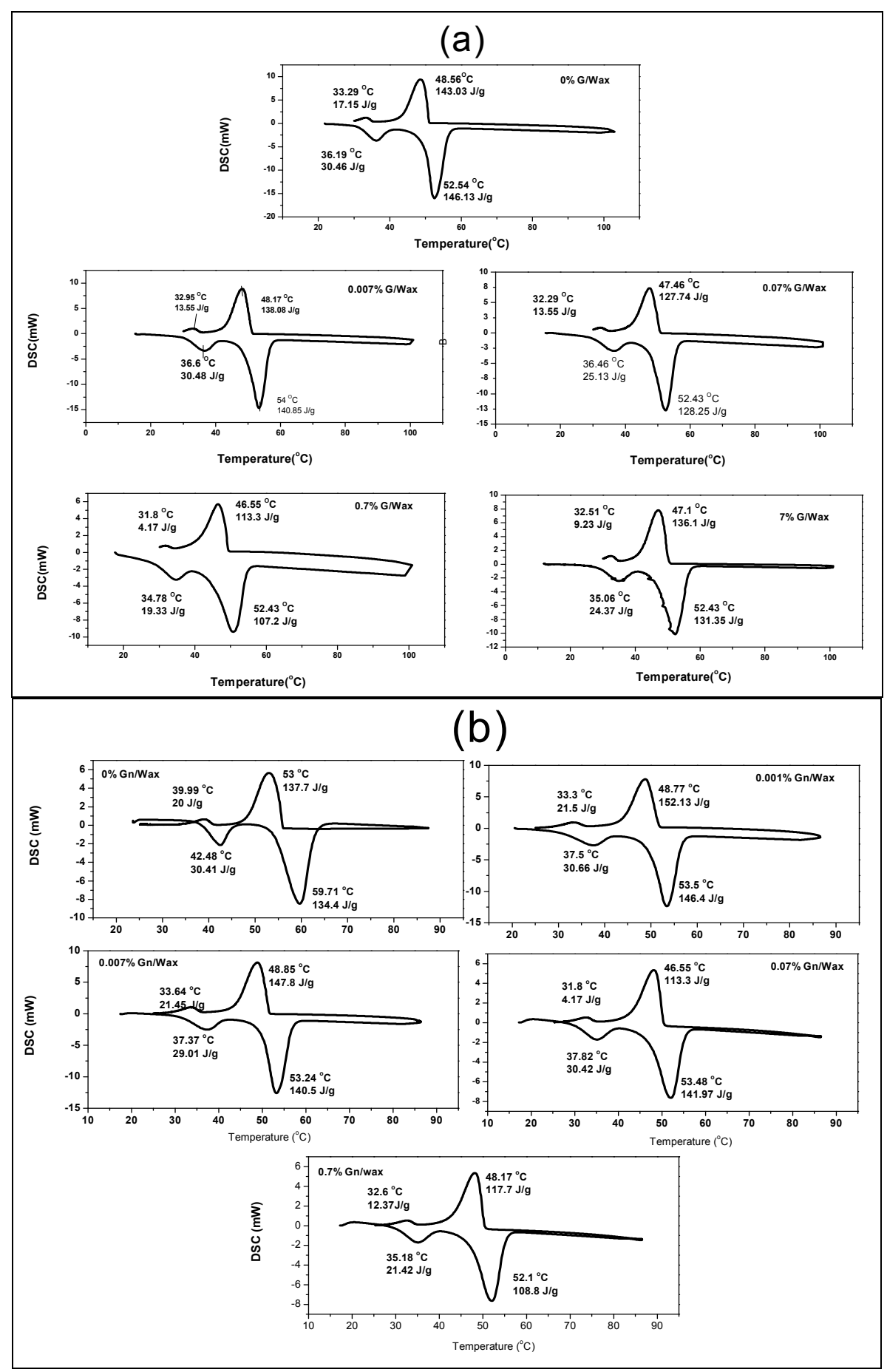

Figure 3. DSC of Paraffin wax composites of different concentrations: (a) G/wax; and (b) Gn/wax. DSC curves showing solid-solid transitions and solid-liquid transitions during heating and cooling phases; the phase change temperatures and latent heat of transitions are indicated.

There is no big fluctuation in the melting and solidification temperatures for graphite-paraffin wax composites, while there is a slight decrease for the melting and solidification temperatures for grapheme-wax composites (Figure 4). Fan et al. [35] recorded a similar variation of the melting and 
solidification temperatures. They observed no clear trend between the melting temperature variation and the loading of carbon nanofillers. They attributed these variations to the filler induced alignment of paraffin molecules surrounding the carbon, which alters the local steric hindrance. Xiang et al. [3] present DSC results that show the latent heat of paraffin nanocomposites were not degraded by adding exfoliated graphite nanoplatelets, while Zhang et al. [33] found that the phase change temperature were very close to that of paraffin while the latent heat of the composite was equal to the latent heat of the paraffin multiplied by its mass fraction [9].
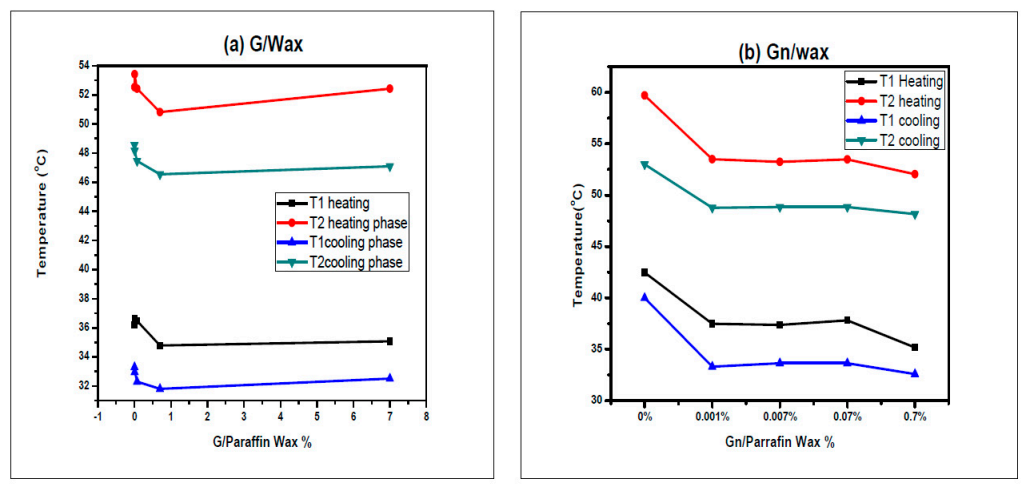

Figure 4. The solid-solid transition temperature, the solid liquid transition temperature during heating and cooling phase for: (a) G/paraffin; and (b) Gn/Paraffin.

The latent heats for solid-solid transition $\mathrm{L}_{1}$ and solid liquid transition $\mathrm{L}_{2}$ are calculated from DSC spectra as the total area under the transition peak of the composite by numerical integration. The latent heat is decreased for paraffin wax composites as the host ratio increases (Figure 5). The latent heat is nearly equivalent to the calculated one based on the value of the latent heat of pure paraffin wax multiplied by (one mass ratio of the host). However, there are discrepancies for higher mass ratios for graphite percentages $0.7 \%$ and $7 \%$ and for Gn percentages $0.07 \%$ and $0.7 \%$. Li et al. [36] observed a decrease of the latent heat of decosane-spongy graphene composite with the graphene addition.

(a)

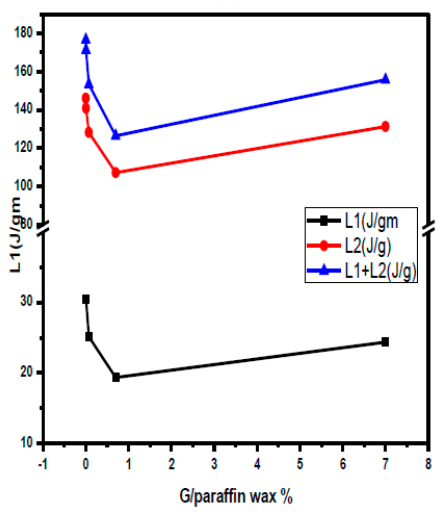

(b)

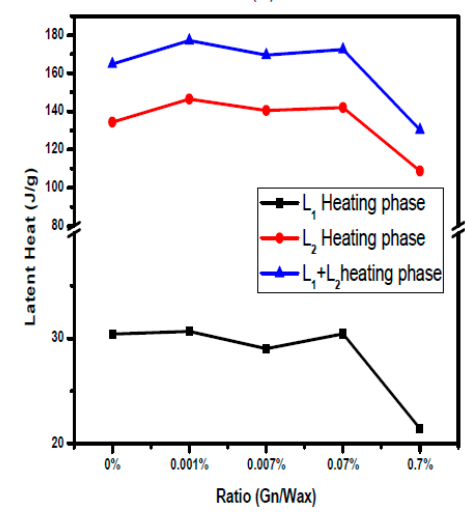

Figure 5. Latent heat during heating phase for solid-solid transition $\mathrm{L}_{1}$ and solid liquid transition $\mathrm{L}_{2}$ and their sum $\mathrm{L}_{1}+\mathrm{L}_{2}$ for: (a) G/wax; and (b) Gn/wax.

Specific heat capacity of composites is calculated with Equation (1) using the DSC data of the composites [37].

$$
\mathrm{C}_{\mathrm{p}}=\mathrm{E} \cdot \mathrm{Q} / \mathrm{R} \cdot \mathrm{M}
$$

where $C_{p}$ is the specific heat capacity, $Q$ is the heat flow, $R$ is the heating rate $(T / t), M$ is the mass of sample, and E is the DSC calibration factor. 
DSC calibration factor $\mathrm{E}$ is calculated knowing the specific heat capacity of paraffin wax $\left(2926 \mathrm{~J} / \mathrm{Kg} \cdot{ }^{\circ} \mathrm{C}\right)$, heat flow, heating rate $(\mathrm{T} / \mathrm{t})\left(10^{\circ} \mathrm{C} / \mathrm{min}\right)$ and mass of the sample. The value of DSC calibration factor is used to find specific heat capacity of other different concentration of graphite or graphene.

The calculated specific heat capacity of paraffin wax composites is decreased as the host concentration (Gn or G) is increased (Figure 6). Thus, a smaller quantity of heat is needed for carbon fillers paraffin composites to raise their temperatures. Both carbon fillers ( $G$ and $G n$ ) have great effects in reducing the specific heat capacity of paraffin wax.

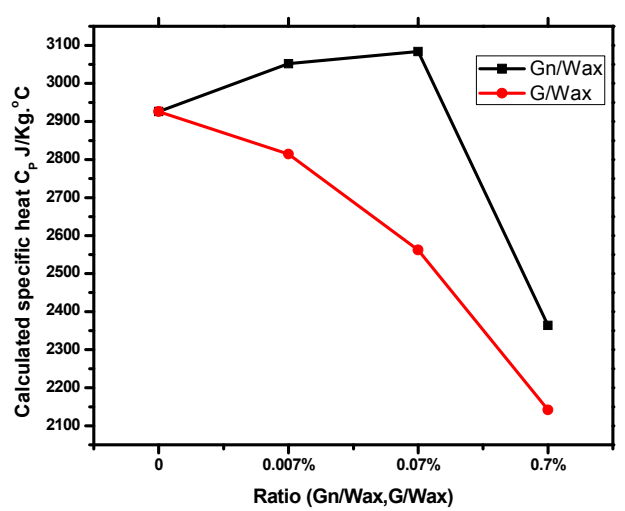

Figure 6. Calculated specific heat capacity of solid-liquid phase transition of composites during heating.

\subsection{Thermo-Optical Switching of Paraffin Wax Spot Composites under Electrical Heating}

Thermo-optical switching transmission is measured under electric heating, as shown in Figure 7. At room temperature, the composites are opaque to light transmission because paraffin wax composite are in solid state. By raising the temperature, the transparency of the samples increases, and the transmission of diode laser under heating is increased.
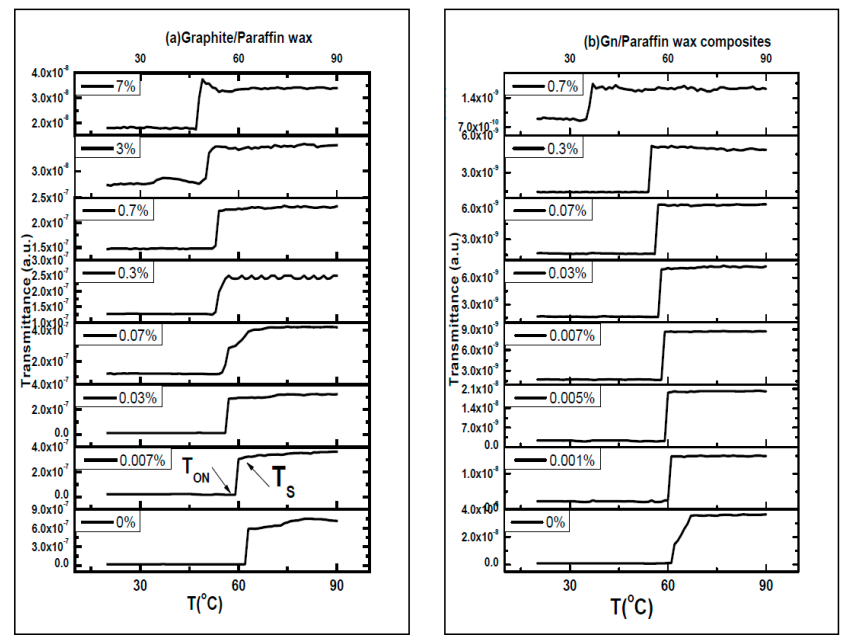

Figure 7. Thermo-optical switching TOS transmission of spots paraffin wax composite spots hosting: (a) graphite; and (b) graphene versus temperature during heating phase. The switching temperature $\left(\mathrm{T}_{\mathrm{ON}}\right)$ and saturation temperature $\left(\mathrm{T}_{\mathrm{S}}\right)$ are indicated.

$\mathrm{T}_{\mathrm{ON}}$ is the temperature at which the temperature starts to increase under heating and $\mathrm{T}_{\mathrm{S}}$ is the temperature at which the transmission saturates. The switching temperature $\left(\mathrm{T}_{\mathrm{ON}}\right)$ and saturation temperature $\left(\mathrm{T}_{\mathrm{S}}\right)$ of paraffin wax-spot composites are deduced from the switching curves shown in Figure 7. 
Paraffin wax-graphite composites spots dispersed in toluene switch at $62,59,56,54.9,52.8,52.8$, 49 and $47^{\circ} \mathrm{C}$ and saturate at $63,59.8,57,57,56.4,54.2,51$ and $48.9^{\circ} \mathrm{C}$ as graphite to paraffin wax ratios increases during heating phase, while spots of paraffin wax-graphene composites switching temperature $\left(\mathrm{T}_{\mathrm{ON}}\right)$ are $60.6,60,59.1,58.5,57,56,53$ and $34{ }^{\circ} \mathrm{C}$ and saturation temperature $\left(\mathrm{T}_{\mathrm{S}}\right)$ are 66 , $61.2,60.5,59.2,58.5,57.4,55$ and $37.4{ }^{\circ} \mathrm{C}$ as the graphene to paraffin wax ratios are increased during heating, as shown in Figure 7.

The relation between $\mathrm{T}_{\mathrm{ON}}$ and $\mathrm{T}_{\mathrm{S}}$ as a function of the composite ratio hosting graphite is almost linear, as shown in Figure 8, The most remarkable values of the switching temperature are at the highest concentration of graphene, and sharp decreases of $\mathrm{T}_{\mathrm{ON}}$ and $\mathrm{T}_{\mathrm{S}}$ are observed. The difference between the switching temperature $T_{\mathrm{ON}}$ and the saturation temperature $\mathrm{T}_{\mathrm{S}}$ is less for graphene/wax composites than that of graphite/wax composites. These findings confirm lowering the temperature rise due to the extreme thermal conductivity of the graphene over that of graphite.
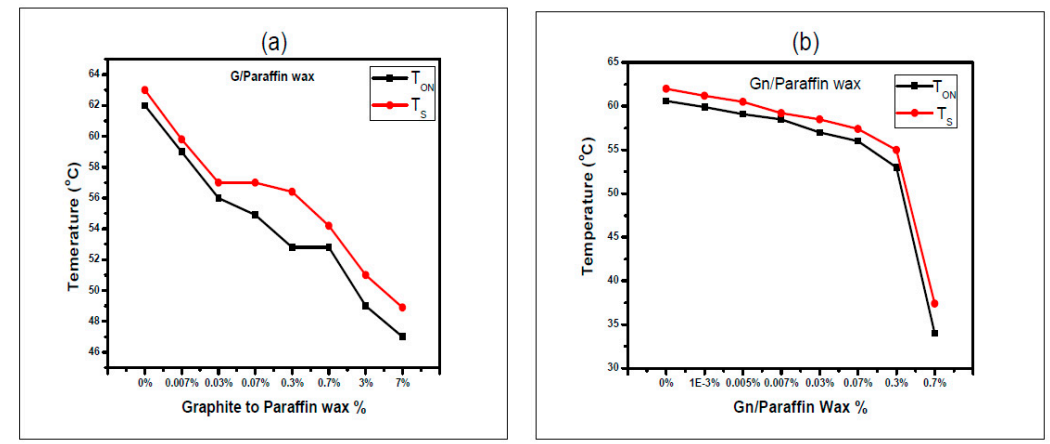

Figure 8. The switching Temperature $T_{\mathrm{ON}}$ and the saturation Temperature $\mathrm{T}_{\mathrm{S}}$ versus: (a) G/Wax; and (b) Gn/Wax, during heating phase.

Figure 9 shows TOS of paraffin wax composite spots versus time during heating phase. As the percent of graphite and graphene in the paraffin composites increases, there is a slight decrease in both the switching time $t_{\mathrm{ON}}$ and the saturation time $\mathrm{t}_{\mathrm{S}}\left(\mathrm{t}_{\mathrm{ON}}\right.$ is the time where the transmission starts to increase and $t_{S}$ is the time where the transmission reaches its maximum value). Switching times $\left(t_{O N}\right)$ of paraffin wax-graphite composite spots dispersed in toluene are 223, 216, 211, 155, 122, 117, 103 and $96 \mathrm{~s}$ and saturation times $\left(\mathrm{t}_{\mathrm{S}}\right)$ are $225,241,213.7,167,139,125,117$ and $115 \mathrm{~s}$, as graphite to paraffin wax percent increases during heating, as shown in Figure 9.
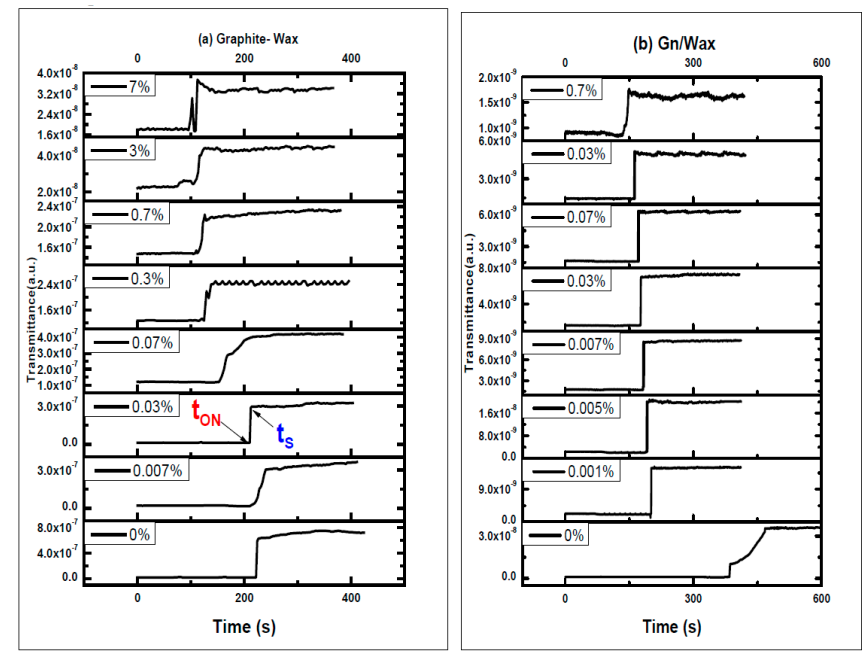

Figure 9. TOS of: (a) paraffin wax-graphite composites spots; and (b) Gn/Paraffin wax versus time during heating phase. Switching time $t_{\mathrm{ON}}$ and saturation time $\mathrm{t}_{\mathrm{S}}$ are indicated. 
The switching $\mathrm{ON}$ time $\left(\mathrm{t}_{\mathrm{ON}}\right)$ and saturation time $\left(\mathrm{t}_{\mathrm{S}}\right)$ of paraffin wax-graphene spot composites are 381.4, 200, 189, 183, 177.8, 170.2, 162 and $137 \mathrm{~s}$ and 389, 203, 192, 185, 180.3, 173, 164 and $151 \mathrm{~s}$. The switching $\mathrm{ON}$ time $\left(\mathrm{t}_{\mathrm{ON}}\right)$ and saturation time $\left(\mathrm{t}_{\mathrm{S}}\right)$ of paraffin wax-graphene spot composites are decreased as graphene to paraffin wax ratios increase during heating, as shown in Figure 10. The most striking result to emerge from the data is that the rising time $\Delta t=\left(t_{S}-t_{O N}\right)$ was enhanced for Gn/Wax spots.
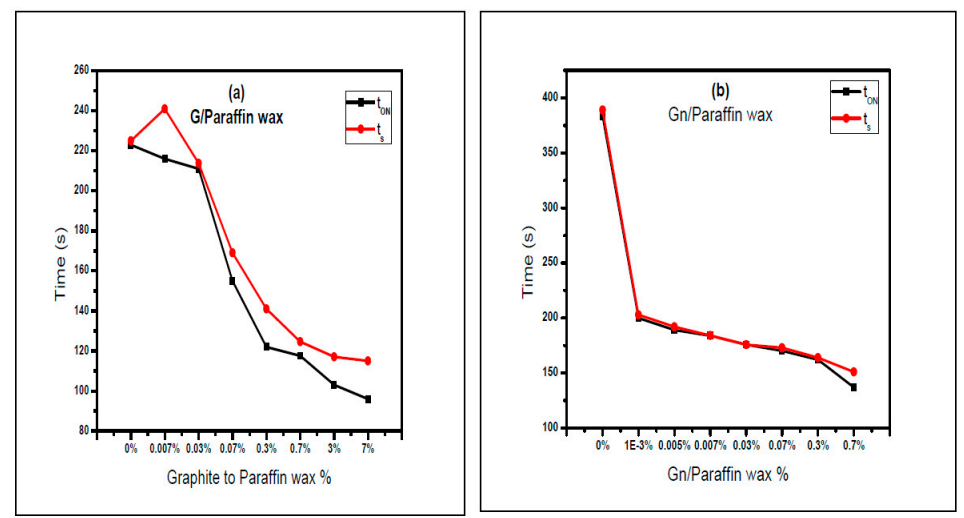

Figure 10. $t_{\mathrm{ON}}$ and $\mathrm{t}_{\mathrm{S}}$ versus (a) G/Wax; (b) Gn/Wax under electric heating.

Thermo-optical parameters of paraffin wax are enhanced with addition of graphene and graphite. A decrease in the switching and saturation temperatures and their corresponding switching on time and saturation time $t_{S}$ are observed. These lead to fast switching as compared to paraffin wax, as the content of carbon fillers in paraffin wax are increased; consequently, the quantity of heat transferred by convection through paraffin wax-carbon filler composites are increased in comparison to that transferred through pure paraffin wax. Once the paraffin wax is completely melted, convection plays a role in the heat transfer. The time necessary for melting is reduced by the role of the natural convection of the thermal conductive fillers. As interpreted by Yu et al. [38], the better performance of $\mathrm{Gn}$ is primarily attributed to its planar structure, which lowers the geometric contribution of phonon mismatch, leading to less phonon scattering at the interfaces between the filler and the matrix material. Consequently, the enhancement of TOS is not only due to high thermal conductive carbon fillers but is also due to the filler-induced alignment of the paraffin molecules that inherently enhances the thermal properties of the paraffin wax.

The observations of TOS transmission cooling curves correspond to those from heating curves. TOS transmission cooling curves are presented in Appendix A.

\subsection{Thermo-Optical Switching of Paraffin Wax Composites under Nd:YAG Laser Heating}

TOS of paraffin wax composite spots in the center of copper capillary tube are studied. Using copper capillary tube is mandatory for the measurements because glass capillary tube broke due to the high power of Nd:YAG laser, while other forms such as Teflon and stainless steel do not match the correct measurements. Copper has larger thermal conductivity and smaller heat capacity than glass, which lead to efficient and fast heat transfer of laser pulses to the paraffin wax composite spots.

When the Nd:YAG laser is off, the sample is opaque. The light coming from diode laser through optical fiber is blocked. Nd:YAG laser $(1064 \mathrm{~nm})$ with high power laser pulses $(110 \mathrm{~mJ})$ is directed normally to the capillary copper tube as a heating source; the heat is transferred from laser beam through the copper wall of the capillary to melt the wax spot. The light, through optical fiber, is passed through the melted spot. Transmission is recorded as a function of time via optical power meter. Recording temperature variation was difficult under laser heating. An estimation of the temperature under laser heating is done in Appendix B. Two series of paraffin wax spot composites using graphite/graphene are studied under laser heating. 
The switching $\mathrm{ON}$ time $\left(\mathrm{t}_{\mathrm{ON}}\right)$ and saturation time $\left(\mathrm{t}_{\mathrm{S}}\right)$ of paraffin wax-graphene composite spots during heating are deduced from the switching curves shown in Figure 11.
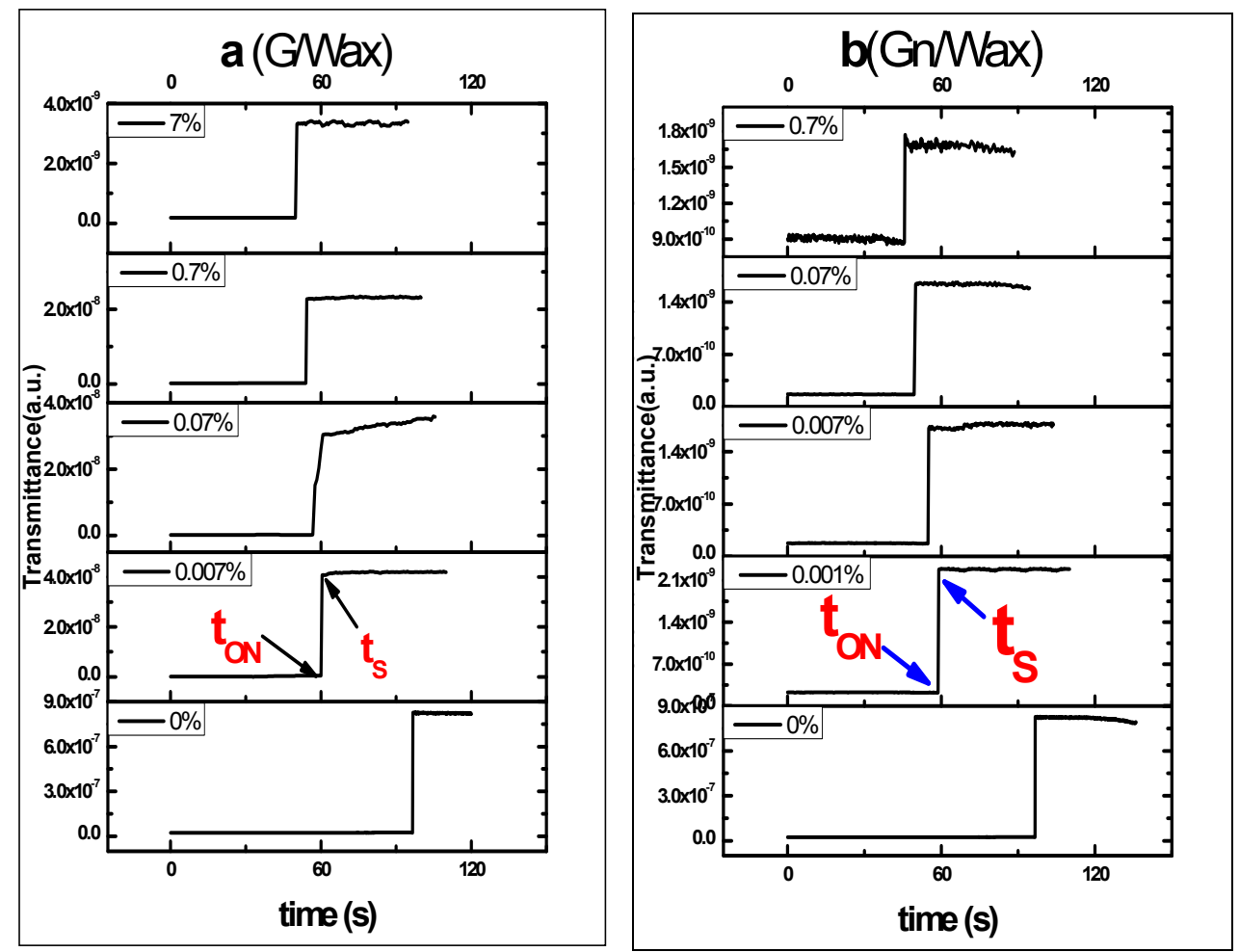

Figure 11. TOS of paraffin wax spots hosting: (a) graphite; and (b) graphene composites versus time for different concentration of host under laser heating. The switching $\mathrm{ON}$ time $\left(\mathrm{t}_{\mathrm{ON}}\right)$ and saturation time $\left(\mathrm{t}_{\mathrm{S}}\right)$ are marked on the figure.

By using Nd:YAG laser as a heating source, paraffin wax-graphite spot composites dispersed in toluene switching on times $\mathrm{T}_{\mathrm{ON}}$ are 95.6, 59.5, 56, 54 and $49.2 \mathrm{~s}$. The saturation time $\mathrm{t}_{\mathrm{S}}$ are 96.7, $60.5,60.8,54.4$ and $50.4 \mathrm{~s}$ with graphite to paraffin wax percentages $0 \%, 0.007 \%, 0.07 \%, 0.7 \%$ and $7 \%$, respectively, during heating phase, as shown in Figure 11.

The switching $\mathrm{ON}$ time ( $\mathrm{t}_{\mathrm{ON}}$ ) of paraffin wax-graphene composite spots under laser heating are $94,58.5,54,49.5$ and $45.6 \mathrm{~s}$. Saturation times ( $\mathrm{t}_{\mathrm{S}}$ ) are $96.7,59.1,55.2,50$ and $45.8 \mathrm{~s}$ with graphene to wax percentages $0 \%, 0.001 \%, 0.007 \%, 0.07 \%$ and $0.7 \%$, respectively, during heating phase.

The switching on time $\left(t_{\mathrm{ON}}\right)$ and measured saturation time $\left(\mathrm{t}_{\mathrm{S}}\right)$ of paraffin wax-graphene spot composites under laser heating are shown in Figure 12. During heating, the total laser exposure time for melting the sample completely is decreased as the carbon filler ratio increases ( $G$ and $G n$ ). The gap between switching and saturation times (rise time $\Delta \mathrm{t}$ ) reaches 0.2 and $0.4 \mathrm{~s}$ for $0.7 \% \mathrm{Gn} / \mathrm{wax}$ and $0.7 \%$ $\mathrm{G} /$ wax, respectively. These results highlight using paraffin wax with best concentrations of $\mathrm{G} / \mathrm{Gn}$ under laser exposure in thermo-optical switching applications.

Thermo-optical switching times are summarized in Table 1 for $0 \%, 0.007 \%, 0.07 \%$ and $0.7 \%$ spots paraffin wax composite under electric and laser heating. Furthermore, a comparison to Ref. [29] of higher mass of paraffin wax is included in the table. The results in Table 1 confirm decreasing the switching times for small mass of paraffin wax composite spots. 

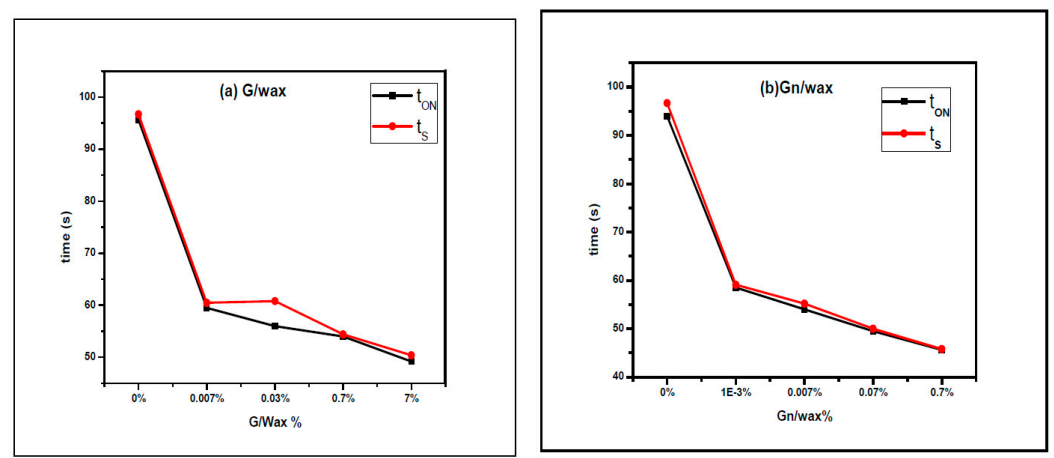

Figure 12. The measured switching $\mathrm{ON}$ time $\left(\mathrm{t}_{\mathrm{ON}}\right)$ and the measured saturation time $\left(\mathrm{t}_{\mathrm{S}}\right)$ of paraffin wax-graphite composites hosting: (a) graphite; and (b) graphene using Nd:YAG laser as a heating source.

Table 1. Thermo-optical switching times of paraffin wax composite spots under electric heating, laser heating in comparison to Ref. [29]. $t_{\mathrm{ON}}$ : the switching on time; $\mathrm{t}_{\mathrm{S}}$ : the saturation time; $\Delta \mathrm{t}$ : rise time.

\begin{tabular}{|c|c|c|c|c|c|c|c|c|c|c|}
\hline \multicolumn{11}{|c|}{ (a) } \\
\hline \multicolumn{11}{|c|}{ G-Paraffin Wax } \\
\hline \multirow[t]{2}{*}{ G/Wax\% } & \multicolumn{3}{|c|}{ Spot under Electric Heating } & \multicolumn{3}{|c|}{ Spot under Laser Heating } & \multirow[t]{2}{*}{$\eta t_{O N}$} & \multirow[t]{2}{*}{$\eta t_{s}$} & \multicolumn{2}{|c|}{ Said et al, Ref. [29] } \\
\hline & $t_{\mathrm{ON}} / \mathrm{s}$ & $t_{S} / s$ & $\Delta \mathrm{t} / \mathrm{s}$ & $\mathrm{t}_{\mathrm{ON}} / \mathrm{s}$ & $t_{S} / s$ & $\Delta \mathrm{t} / \mathrm{s}$ & & & $t_{\mathrm{ON}} / \mathrm{s}$ & $t_{\mathrm{S}} / \mathrm{s}$ \\
\hline 0 & 223 & 225 & 2 & 95.6 & 96.7 & 1.1 & 57.1 & 57 & 480.3 & 501 \\
\hline 0.007 & 216 & 241 & 25 & 59.5 & 60.5 & 1 & 72.5 & 74.9 & 347.8 & 352 \\
\hline 0.07 & 155 & 167 & 12 & 56 & 60.8 & 4.8 & 63.9 & 63.6 & 490 & 497 \\
\hline 0.7 & 117 & 125 & 8 & 54 & 54.4 & 0.4 & 53.9 & 56.5 & 592 & 597 \\
\hline \multicolumn{11}{|c|}{ (b) } \\
\hline \multicolumn{11}{|c|}{ Gn-Paraffin Wax } \\
\hline \multirow[t]{2}{*}{ Gn/Wax $\%$} & \multicolumn{3}{|c|}{ Spot under Electric Heating } & \multicolumn{3}{|c|}{ Spot under Laser Heating } & $\eta t_{\text {ON }}$ & $\eta t_{s}$ & \multicolumn{2}{|c|}{ Ref. [29] } \\
\hline & $t_{\mathrm{ON}} / \mathrm{s}$ & $t_{S} / s$ & $\Delta \mathrm{t} / \mathrm{s}$ & $\mathrm{t}_{\mathrm{ON}} / \mathrm{s}$ & $t_{S} / s$ & $\Delta \mathrm{t} / \mathrm{s}$ & & & $t_{\mathrm{ON}} / \mathrm{s}$ & $\mathbf{t}_{\mathrm{S}} / \mathrm{s}$ \\
\hline 0 & 381.4 & 389 & 7.6 & 94 & 96.7 & 2.7 & 75.4 & 75.1 & 488.1 & 495.1 \\
\hline 0.007 & 183 & 185 & 2 & 54 & 55.2 & 1.2 & 70.5 & 70 & 409 & 430 \\
\hline 0.07 & 170.2 & 173 & 2.8 & 49.5 & 50 & 0.5 & 70.9 & 71.1 & 258.6 & 267.6 \\
\hline 0.7 & 137 & 151 & 14 & 45.6 & 45.8 & 0.2 & 66.7 & 69.7 & 149.9 & 156.1 \\
\hline
\end{tabular}

By comparing $\mathrm{t}_{\mathrm{ON}}$ and $\mathrm{t}_{\mathrm{S}}$ for graphite-wax spots using electric heating and laser heating for the above percentages $0 \%, 0.007 \%, 0.07 \%$ and $0.7 \%$, a much decrease in $t_{O N}$ and $t_{S}$ are observed under laser heating. An enhancement factor is calculated by;

$$
\eta t_{\text {ON }}=\left|\frac{t_{\text {ON }} \text { under laser heating }-t_{\text {ON }} \text { under electric heating }}{t_{\text {ON }} \text { under elctric heating }}\right| \times 100 \%
$$

( $t_{\mathrm{ON}}$ or $\mathrm{t}_{\mathrm{S}}$ under electric heating) for switching and saturation times, respectively.

Equation (2) represents the difference between the switching times of wax spots hosting carbon fillers under laser heating and electric heating divided by the switching time for the same filler concentration under electric heating. Similarly, the time enhancement factor for $t_{S}$ is $\eta t_{S}$.

For $\mathrm{G} /$ wax, the enhancements for $\mathrm{t}_{\mathrm{ON}}$ were $57 \%, 72.5 \%, 63.9 \%$, and $53.9 \%$, while the enhancements for $\mathrm{t}_{\mathrm{S}}$ for were $75.4 \%, 70.6 \%, 70.9 \%$, and $66.7 \%$ for $0 \%, 0.007 \%, 0.07 \%$ and $0.7 \%$, respectively.

For Gn/wax, the enhancements for $\mathrm{t}_{\mathrm{ON}}$ were $75.4 \%, 70.5 \%, 70.9 \%$, and $66.7 \%$, while the enhancements for $t_{S}$ for were $75.1 \%, 70 \%, 71.1 \%$, and $69.7 \%$ for the above-mentioned ratios.

Significantly, In addition to thermal heating effect of laser which transfers heat effectively in a shorter time of few milliseconds, enhancements of switching times of Gn/wax are greater for those of $\mathrm{G} /$ wax due to the extreme thermal conductivity of Gn. 
In this work, the TOS based on the transmission change undergoing phase change material (PCM) is investigated, the switching efficiency are enhanced by adding high thermal conductive fillers to PCM.

In the literature, thermo-optic effect depends on the refractive index variation of the material due to temperature variation of the material. The most used materials to fabricate TOS are polymers, silica and silicon. Conventional thermo-optic waveguide switches are usually based on the Y-branch, Mach-Zehnder interferometer (MZI) and Total Internal Reflection (TIR). Y-branch digital optical switch (Y-branch DOS) principle lies on refractive index exchange of light input into the "base" or trunk of the $\mathrm{Y}$ and the output branches. In Mach-Zehnder interferometer, heating one arm of the interferometer causes its refractive index to change; hence, a variation of the optical path between the two interferometer arms is experienced. Consequently, a phase difference between the light beams may be constructive or destructive interference and selection of the output can be maximized or minimized. While thermo optic switch based on TIR depends on changing the path of light passing from a prism; with increasing the prism temperature, the refractive index of the prism increases. Consequently, the critical angle decreases and becomes less than the incident angle; hence, the incident light is totally reflected in other output $[1,2]$.

Y branch TOS and MZI TOS configurations have complementary advantages and disadvantages. $Y$ branch structure has the advantages of larger operation bandwidth and medium device size, but has the disadvantages of larger power consumption. MZI has the advantages of low power consumption. However, it has the disadvantages of narrower operation bandwidth and larger device size [39].

Table 2 summarizes some optical switching configurations based on different materials. The switching time is reported, Optical switching speed ranges from microsecond up to millisecond depending on the switch design. The main disadvantage of our investigated thermo-optic switch is the slow switching in comparison to other TOS configurations. There are two ways to decrease the switching time: the first is by decreasing the mass of paraffin wax spot, and the second is by enhancing the thermal properties of paraffin wax.

Table 2. Some optical switching configuration based on different materials, Digital thermo optic switch: DOS; Thermo-optic switch: TOS; total internal reflection: TIR; and Mach-Zehnder interferometer: MZI.

\begin{tabular}{ccccc}
\hline Configuration & Material & Switch Time & Ref. & Year \\
\hline DOS & polymer & $10 \mathrm{~ms}$ & Noh et al. [40] & 2006 \\
TOS based on TIR & $\begin{array}{c}\text { polymer } \\
\text { Yhiral azobenzene-containing } \\
\text { polyurethane (CACPU) }\end{array}$ & $12 \mathrm{~ms}$ & Han et al. [41] & 2012 \\
Y branch & chiral azobenzene-containing & Ye et al. [42] & 2013 \\
Molyurethane (CACPU) & 2 ms & Ye et al. [42] & 2013 \\
TOS based on TIR & Polyimide waveguide & Not reported & Yang et al. [43] & 2002 \\
Liquid-optical switch & Conductive liquids & $132 \mathrm{~ms}$ & Liu et al. [44] & 2015 \\
IR switch & glycerol droplet & $200 \mathrm{~ms}$ & Ren et al. [45] & 2012 \\
TOS (MZI) & Silicon on insulator (SOI) & $141 \mu \mathrm{s}$ & Sun et al. [46] & 2010 \\
\hline
\end{tabular}

Our thermo-optical switching design can be useful for cost-effective switching designs but it suffers low switching time. The investigated technique is simple, low cost and low alignment compared to other TOS high complex structures. Our work clearly has some limitations. Nevertheless, it could be a springboard to using phase change materials as thermo-optic switch.

\section{Conclusions}

This paper has given an account of thermo-optical switching of paraffin wax spots hosting carbon fillers (G/Gn). The morphology of paraffin composites was determined via SEM. The images show better homogeneity for the prepared paraffin composites. DSC measurements show phase change temperatures of solid-solid and solid-liquid transitions of paraffin wax composites. The latent heat 
and specific heat capacity are calculated based on DSC data. We have confirmed that a small quantity of heat is needed to raise the composite temperature from specific heat capacity calculations.

The evidence from this study points towards the idea of enhancing thermo-optic switching of paraffin wax spot composites hosting G/Gn under electric heating as well as Nd:YAG laser heating. We have obtained comprehensive results demonstrating the switching time $t_{\mathrm{ON}}$ and saturation time $\mathrm{ts}_{\mathrm{S}}$ are enhanced for paraffin wax composites under laser heating. The heating by Nd:YAG laser led to faster switching than using continuous heating (electric heater). The decreases in rise time $\left(t_{S}-t_{O N}\right)$ of the switches were up to 0.2 and $0.4 \mathrm{~s}$ for paraffin wax spots hosting graphene and graphite, respectively. The enhancement of lowering the switching parameters is due to the high thermal effect of high power laser pulses. The upshots of these measurements support using paraffin wax (PCM) hosting graphite or graphene as thermo optical sensing material for Thermo-optical Switching (TOS) device applications.

Acknowledgments: The authors thank the National Institute of Laser Enhanced Sciences (NILES) for offering facilities during this work, The authors thank Mohammed Hafez for using Nd:YAG laser in his laboratory. This research did not receive any specific grant from funding agencies in the public, commercial, or not-for-profit sectors.

Author Contributions: Gamal Abdel Fattah conceived and designed the experiments; Asmaa Said performed the experiments; Abeer Salah and Gamal Abdel Fattah analyzed the data; and Abeer Salah wrote the paper.

Conflicts of Interest: The authors declare no conflict of interest. The founding sponsors had no role in the design of the study; in the collection, analyses, or interpretation of data; in the writing of the manuscript, and in the decision to publish the results.

\section{Appendix A}

\section{Appendix A.1. TOS Cooling Curves of Paraffin Wax Spot Composites under Electric Heating}

As shown in Figure A1, $\mathrm{T}_{\mathrm{sc}}$ is the temperature at which the transmitted intensity starts to decrease while $\mathrm{T}_{\text {off }}$ is the temperature at which the transmitted intensity is blocked and the composite returns in the solid phase. There are fluctuations of $\mathrm{T}_{\mathrm{sc}}$ and $\mathrm{T}_{\text {off }}$ in the cooling phase as the concentration of Graphite increases, while the Gn shows a greater decrease of $\mathrm{T}_{\mathrm{sc}}$ and $\mathrm{T}_{\text {off }}$ as its percent increases in the composite.
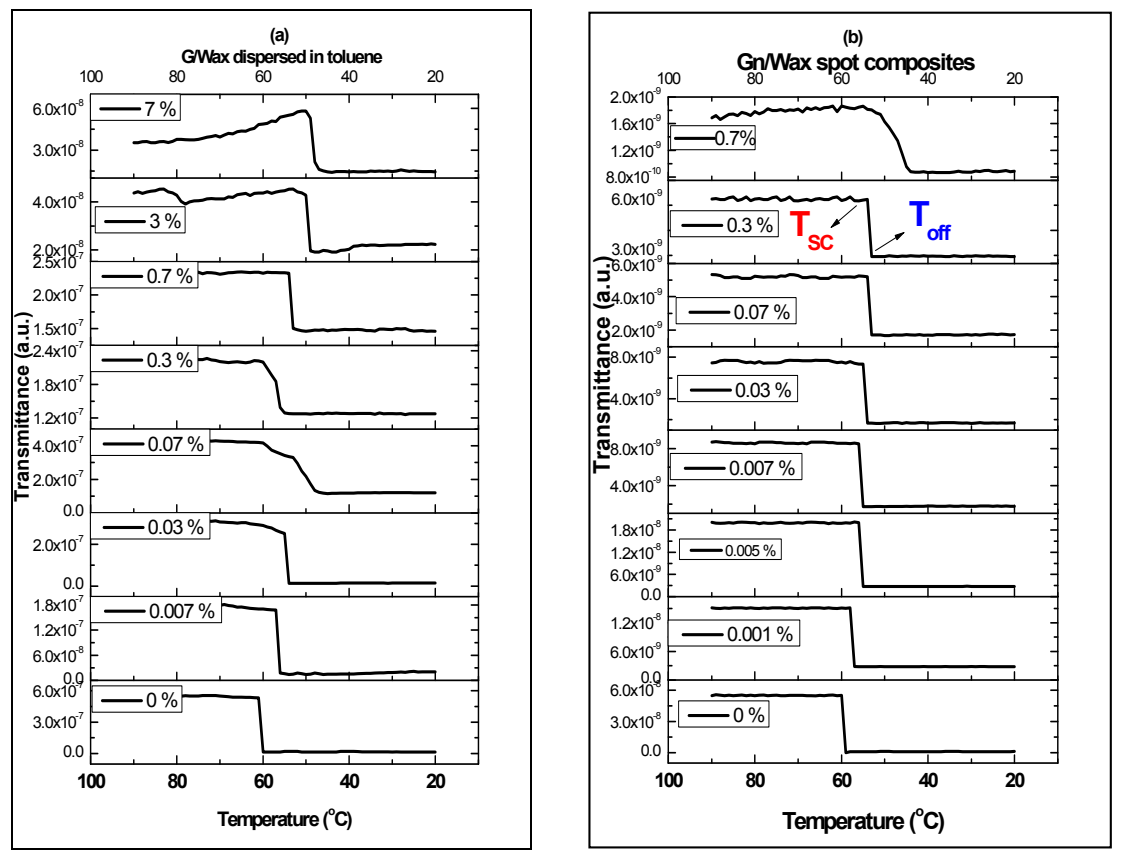

Figure A1. TOS cooling curves of paraffin wax-spot composites hosting: (a) graphite dispersed in toluene; and (b) graphene versus temperature. $\mathrm{T}_{\mathrm{sc}}$ and $\mathrm{T}_{\text {off }}$ are marked in the figure. 
The $\mathrm{T}_{\mathrm{SC}}$ of spots paraffin wax-graphite composites dispersed in toluene were at $62,57,55,60,52$, 52,49 and $47^{\circ} \mathrm{C}$ and $\mathrm{T}_{\text {off }}$ were at $60,56,54,48,60,53,48$ and $46^{\circ} \mathrm{C}$ as graphite to paraffin wax ratios increase, respectively, during cooling phase.

$\mathrm{T}_{\mathrm{SC}}$ and $\mathrm{T}_{\mathrm{off}}$ of spots paraffin wax-graphene composites, which were at 58, 56, 55, 55, 54, 53, 53 and $44^{\circ} \mathrm{C}$ and $60,58,56,56,55,54,54$ and $52^{\circ} \mathrm{C}$, respectively, are decreased as graphene to paraffin wax ratios are increased during cooling.

$t_{s c}$ is the time at which the transmitted intensity starts to decrease at corresponding temperature $\mathrm{T}_{\mathrm{sc}}$ while $\mathrm{t}_{\mathrm{off}}$ is the time at which the transmitted intensity is blocked at corresponding temperature $\mathrm{T}_{\text {off }}$ and the composite returns to the solid phase.

$\mathrm{t}_{\mathrm{sc}}$ and $\mathrm{t}_{\mathrm{off}}$ of spots paraffin wax-graphite composites dispersed in toluene were 308.27, 163.04, 197.38, 151.4, 146.47, 181.86, 180.38 and 158.19 s and 328.31, 219.86, 214.24, 252.4, 178.20, 218.01, 204.06 and $173.5 \mathrm{~s}$ as graphite concentrations to paraffin wax ratios increases, respectively, during cooling phase.

The $t_{\mathrm{sc}}$ and $t_{\text {off }}$ of spots paraffin wax-graphene composites were 315.37, 209.84, 203.12, 201.47, 197.38, 189.80, 186.50 and $180.5 \mathrm{~s}$ and 327.5, 214.79, 204.77, 206.55, 203.42, 193.10, 183.08 and $234.12 \mathrm{~s}$, respectively, for the mentioned concentrations (Figure A2).
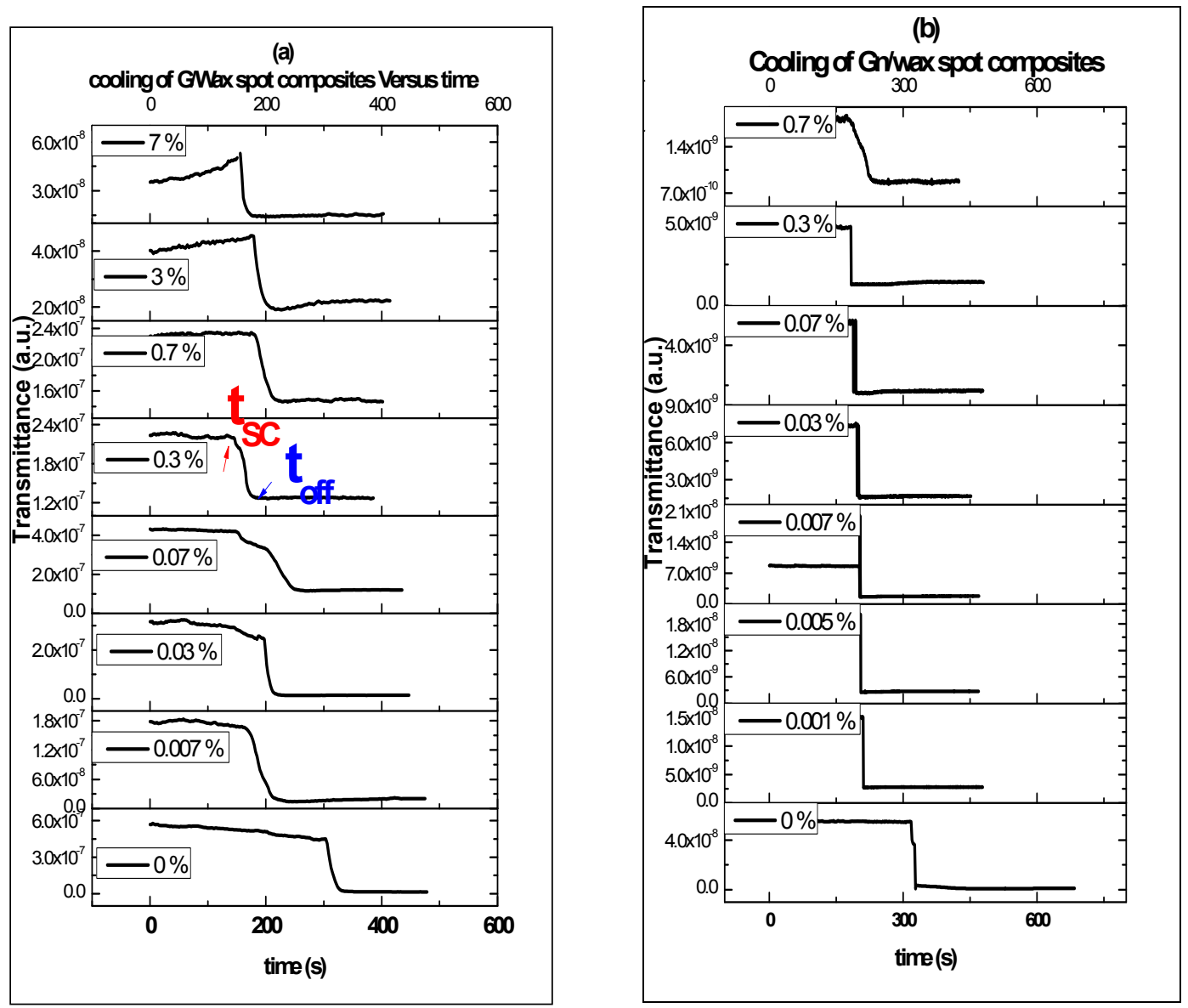

Figure A2. TOS cooling curves versus time of paraffin wax spot composites hosting: (a) G; and (b) Gn.

Appendix A.2. TOS Cooling Phases of Paraffin Wax Spot Composites after Exposure to Nd:YAG Laser Pulses

By switching off Nd:YAG pulsed laser, the times $\mathrm{t}_{\mathrm{SC}}$ and toff of spots paraffin wax-graphite composites dispersed in toluene are 72.9, 70.8, 64.8, 61 and $55.2 \mathrm{~s}$ and 73.9, 72.6, 65.2, 62 and $56.4 \mathrm{~s}$ for graphite to paraffin wax percentages $0,0.007,0.07,0.7$ and 7 , respectively, during cooling phase, as shown in Figure A3. 
$\mathrm{t}_{\mathrm{SC}}$ and $\mathrm{t}_{\mathrm{off}}$ of spots paraffin wax-graphene composite were $72.5,62.8,57.2,50.8$ and $35.4 \mathrm{~s}$ and $73.9,64.4,58,52.6$ and $36.6 \mathrm{~s}$ for graphene to paraffin wax percentages $0,0.001,0.007,0.07$ and 0.7 , respectively, during cooling, as shown in Figure A3.
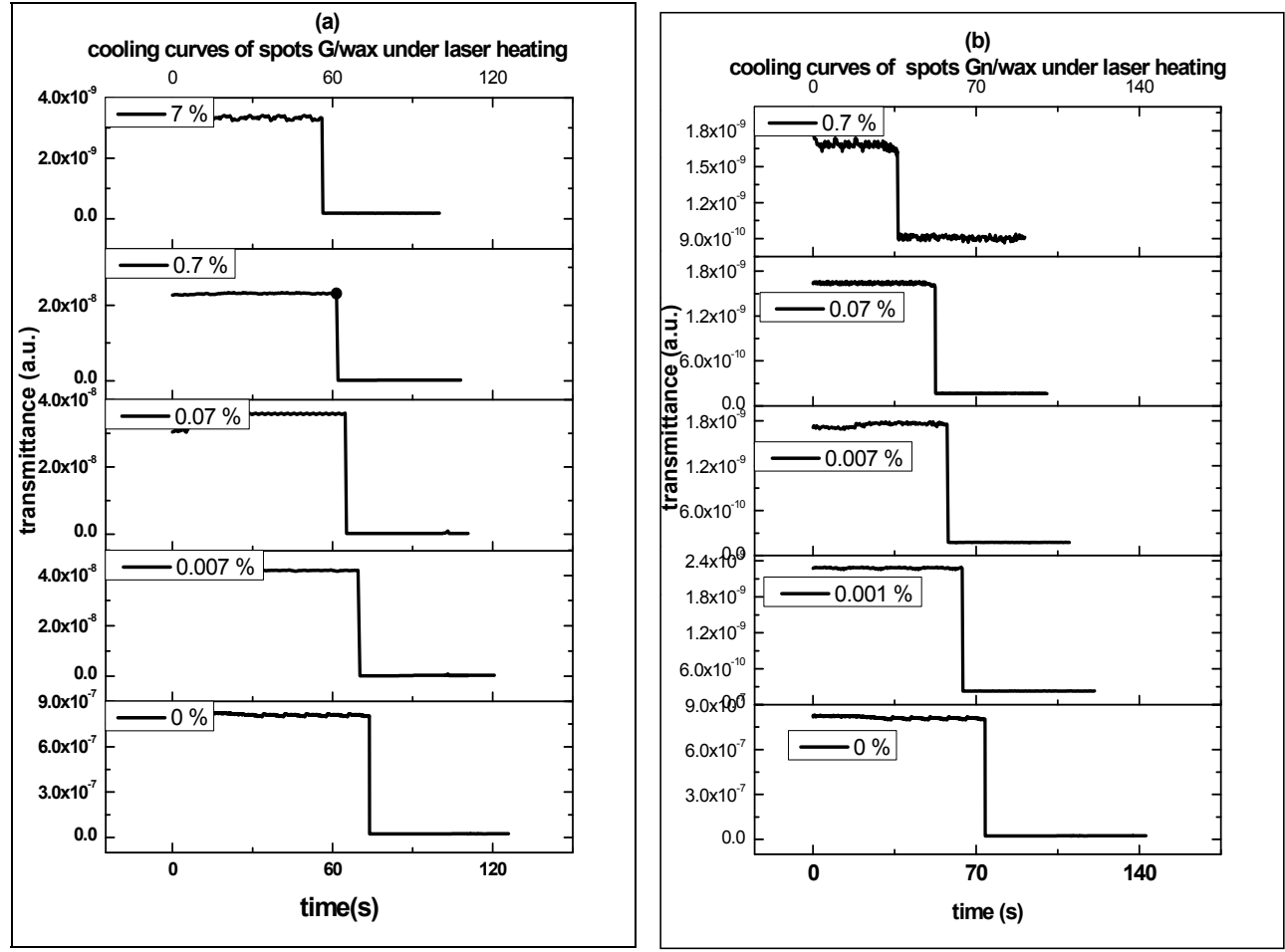

Figure A3. TOS cooling curves after laser heating of paraffin wax spot composites hosting: (a) G; and (b) Gn.

The cooling times $t_{\mathrm{SC}}$ and $\mathrm{t}_{\mathrm{off}}$ are sharply decreased as the concentrations of the carbon filler are increased (Figure A4). The carbon fillers enhance the switching times in the heating and cooling phases.
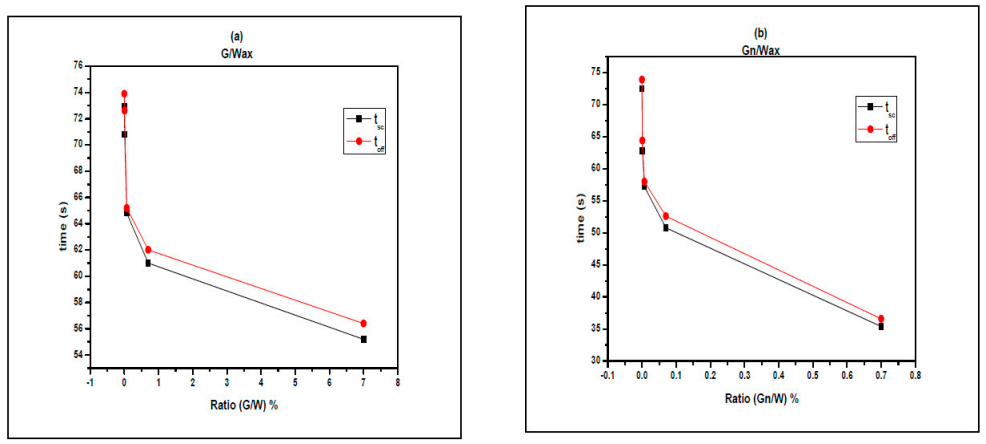

Figure A4. The measured times $t_{s c}$ and $t_{\text {off }}$ of paraffin wax-graphite spot composites hosting: (a) graphite; and (b) graphene during cooling after using Nd:YAG laser.

\section{Appendix B}

Estimation of Melting Temperature $T_{m}$ Using TOS Measurements under Laser Heating

We assumed that the sample under study is exposed to number of laser pulses $\mathrm{N}$ :

$$
\mathrm{N}=\mathrm{FRR} \times \mathrm{t}_{\mathrm{ON}}+\mathrm{t}_{\mathrm{s}} / 2
$$


where FRR is frequency Repetition Rate $(10 \mathrm{~Hz}), \mathrm{t}_{\mathrm{ON}}$ is the switching $\mathrm{ON}$ time where the transmitted intensity starts to increase, and $t_{s}$ is the saturation time where the transmitted intensity reaches to maximum. We assumed the melting temperature $T_{m}$ at time $t_{O N}+t_{s} / 2$, assuming that paraffin wax is melted exactly.

The incident energy after $\mathrm{N}$ laser pulses on the center of the sample can be calculated from the following equation:

$$
\mathrm{Q}=\text { energy pulse } \times \mathrm{N}
$$

The loss of energy is estimated to be from reflection and mismatching between laser beam area and copper capillary tube area $\mathrm{Q}$ loss.

The effective energy $Q_{\text {eff }}$. transferred to the composite can be calculated by:

$$
Q_{\text {eff. }}=Q-Q \text { loss }
$$

Melting temperature can be calculated using TOS transmission measurements under pulsed laser heating:

$$
Q_{\text {eff. }}=\mathrm{m}_{1} \times \mathrm{c}_{1} \times \Delta \mathrm{T}_{1}+\mathrm{m}_{2} \times \mathrm{c}_{2} \times \Delta \mathrm{T}_{2}+\mathrm{m}_{2} \mathrm{~L}
$$

where

- $\mathrm{m}_{1}$ is the mass of copper sheet and $\mathrm{m}_{2}$ are the mass paraffin wax-graphite or graphene dot composites.

- $\quad C_{1}$ and $C_{2}$ are specific heat capacity of copper sheet and paraffin wax-graphite or graphene dot composites, respectively.

- $\quad \mathrm{L}$ is the latent heat of paraffin wax composites calculated from DSC measurements.

- $\Delta \mathrm{T}=\mathrm{T}_{\mathrm{m}}-\mathrm{T}_{\mathrm{i}}$ where $\mathrm{T}_{\mathrm{i}}=$ Troom $=30^{\circ} \mathrm{C}$.

- Neglect the second term $\mathrm{m}_{2} \times \mathrm{c}_{2} \times \Delta \mathrm{T}_{2}$ due to the small weight of mixture (wax + graphite or graphene).

- The melting temperature is estimated as a midpoint between $t_{\mathrm{ON}}$ and $\mathrm{t}_{\mathrm{S}}$.

- The effective area used in calculation as a ratio of laser beam area to surface area of the copper capillary tube.

- The calculated value of the specific heat is from DSC measurement for paraffin wax-graphite or graphene ratio.

Figure A5 shows the estimated melting temperature of paraffin wax spot composites. $T_{m}$ is decreased as the carbon filler increases in the composite under laser exposure, which is attributed to the high thermal conductivities of the G and Gn.
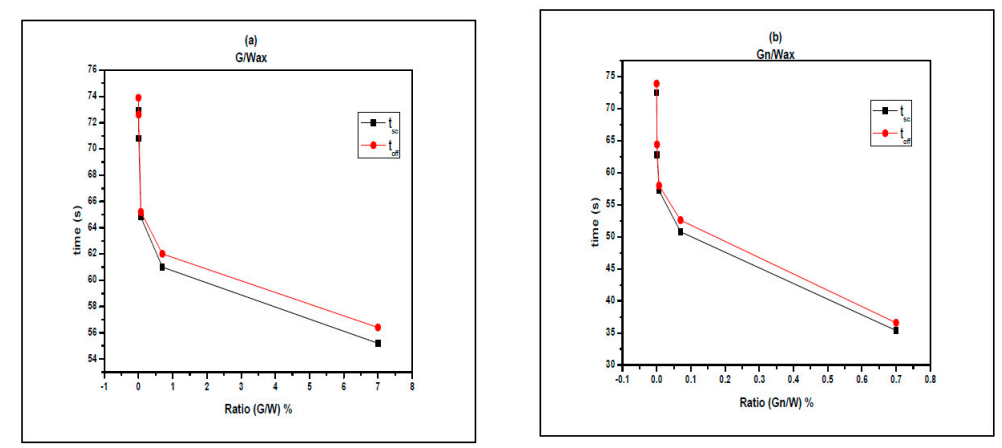

Figure A5. Estimated melting temperature ( $\left.\mathrm{T}_{\mathrm{m}}\right)$ of: (a) graphite/wax (\%); and (b) graphene/wax (\%) during heating by using Nd:YAG laser as a heating source. 


\section{References}

1. Coppola, G.; Sirleto, L.; Rendina, I.; Iodice, M. Advance in thermo-optical switches: Principles, materials, design, and device structure. Opt. Eng. 2011, 50. [CrossRef]

2. Stegmaier, M.; Ríos, C.; Bhaskaran, H.; Pernice, W.H.P. Thermo-optical Effect in Phase-Change Nanophotonics. ACS Photonics 2016, 3, 828-835. [CrossRef]

3. Xiang, J.; Drzal, L.T. Investigation of exfoliated graphite nanoplatelets $(x \mathrm{GnP})$ in improving thermal conductivity of paraffin wax-based phase change material. Sol. Energy Mater. Sol. Cells 2011, 95, 1811-1818. [CrossRef]

4. Mhike, W.; Focke, W.W.; Mofokeng, J.P.; Luyt, A.S. Thermally conductive phase-change materials for energy storage based on low-density polyethylene, soft Fischer-Tropsch wax and graphite. Thermochim. Acta 2012, 527, 75-82. [CrossRef]

5. Chen, Z.; Shan, F.; Cao, L.; Fang, G. Preparation and thermal properties of n-octadecane/molecular sieve composites as form-stable thermal energy storage materials for buildings. Energy Build. 2012, 49, 423-428. [CrossRef]

6. Ukrainczyk, N.; Kurajica, S.; Šipušić, J. Thermophysical Comparison of Five Commercial Paraffin Waxes as Latent Heat Storage Materials. Chem. Biochem. Eng. Q. 2010, 24, 129-137.

7. Li, M. A nano-graphite/paraffin phase change material with high thermal conductivity. Appl. Energy 2013, 106, 25-30. [CrossRef]

8. Chen, Y.J.; Nguyen, D.D.; Shen, M.Y.; Yip, M.C.; Tai, N.H. Thermal characterizations of the graphite nanosheets reinforced paraffin phase-change composites. Compos. Part A Appl. Sci. Manuf. 2013, 44, 40-46. [CrossRef]

9. Sarı, A.; Karaipekli, A. Thermal conductivity and latent heat thermal energy storage characteristics of paraffin/expanded graphite composite as phase change material. Appl. Therm. Eng. 2007, 27, 1271-1277. [CrossRef]

10. Aadmi, M.; Karkri, M.; Hammouti, M.E. Heat transfer characteristics of thermal energy storage of a composite phase change materials: Numerical and experimental investigations. Energy 2014, 72, 381-392. [CrossRef]

11. Xia, L.; Zhang, P. Thermal property measurement and heat transfer analysis of acetamide and acetamide/expanded graphite composite phase change material for solar heat storage. Sol. Energy Mater. Sol. Cells 2011, 95, 2246-2254. [CrossRef]

12. Wang, X.; Guo, Q.; Zhong, Y.; Wei, X.; Liu, L. Heat transfer enhancement of neopentyl glycol using compressed expanded natural graphite for thermal energy storage. Renew. Energy 2013, 51, 241-246. [CrossRef]

13. Baradaran, S.; Moghaddam, E.; Basirun, W.J.; Mehrali, M.; Sookhakian, M.; Hamdi, M.; Moghaddam, M.R.N.; Alias, Y. Mechanical properties and biomedical applications of a nanotube hydroxyapatite-reduced graphene oxide composite. Carbon 2014, 69, 32-45. [CrossRef]

14. Tamilarasan, P.; Ramaprabhu, S. Graphene based all-solid-state supercapacitors with ionic liquid incorporated polyacrylonitrile electrolyte. Energy 2013, 51, 374-381. [CrossRef]

15. Pop, E.; Varshney, V.; Roy, A.K. Thermal properties of graphene:Fundamentals and applications. MRS Bull. 2012, 37, 1273-1281. [CrossRef]

16. Zhu, Y.; Murali, S.; Cai, W.; Li, X.; Suk, J.W.; Potts, J.R.; Ruoff, R.S. Graphene and graphene oxide: synthesis, properties, and applications. Adv. Mater. 2010, 22, 3906-3924. [CrossRef] [PubMed]

17. Jana, P.; Fierro, V.; Pizzi, A.; Celzard, A. Thermal conductivity improvement of composite carbon foams based on tannin-based disordered carbon matrix and graphite fillers. Mater. Des. 2015, 83, 635-643. [CrossRef]

18. Zhong, Y.; Guo, Q.; Li, L.; Wang, X.; Song, J.; Xiao, K.; Huang, F. Heat transfer improvement of Wood's alloy using compressed expanded natural graphite for thermal energy storage. Sol. Energy Mater. Sol. Cells 2012, 100, 263-267. [CrossRef]

19. Yu, Z.T.; Fang, X.; Fan, L.W.; Wang, X.; Xiao, Y.Q.; Zeng, Y.; Xu, X.; Hu, Y.C.; Cen, K.F. Increased thermal conductivity of liquid paraffin-based suspensions in the presence of carbon nano-additives of various sizes and shapes. Carbon 2013, 53, 277-285. [CrossRef]

20. Jiang, X.; Luo, R.; Peng, F.; Fang, Y.; Akiyama, T.; Wang, S. Synthesis, characterization and thermal properties of paraffin microcapsules modified with nano- $\mathrm{Al}_{2} \mathrm{O}_{3}$. Appl. Energy 2015, 137, 731-737. [CrossRef] 
21. Evgin, T.; Koca, H.D.; Horny, N.; Turgut, A.; Tavman, I.H.; Chirtoc, M.; Omastová, M.; Novak, I. Effect of aspect ratio on thermal conductivity of high density polyethylene/multi-walled carbon nanotubes nanocomposites. Compos. Part. Appl. Sci. Manuf. 2016, 82, 208-213. [CrossRef]

22. Liang, W.; Zhang, G.; Sun, H.; Chen, P.; Zhu, Z.; Li, A. Graphene-nickel/n-carboxylic acids composites as form-stable phase change materials for thermal energy storage. Sol. Energy Mater. Sol. Cells 2015, 132, 425-430. [CrossRef]

23. Fang, X.; Fan, L.W.; Ding, Q.; Yao, X.L.; Wu, Y.Y.; Hou, J.F.; Wang, X.; Yu, Z.T.; Cheng, G.H.; Hu, Y.C. Thermal energy storage performance of paraffin-based composite phase change materials filled with hexagonal boron nitride nanosheets. Energy Convers. Manag. 2014, 80, 103-109. [CrossRef]

24. Wurster, S.; Bigl, S.; Cordill, M.J.; Kiener, D. Accelerated thermo-mechanical fatigue of copper metallizations studied by pulsed laser heating. Microelectron. Eng. 2017, 167, 110-118. [CrossRef]

25. Chowdhury, M.N.; Kim, J.R.; Hong, S.T.; Jung, J.W.; Han, H.N.; So, S.W. Tailoring of Mechanical Properties of Indirect Hot Stamping Steel Tubes by Laser Assisted Local Rapid Heating. J. Iron Steel Res. Int. 2016, 23, 949-954. [CrossRef]

26. Vilanova-Martínez, P.; Hernández-Velasco, J.; Landa-Cánovas, A.R.; Agulló-Rueda, F. Laser heating induced phase changes of $\mathrm{VO}_{2}$ crystals in air monitored by Raman spectroscopy. J. Alloys Compd. 2016, 661, 122-125. [CrossRef]

27. Hu, Y.; Luo, M.; Yao, Z. Increasing the capability of laser peen forming to bend titanium alloy sheets with laser-assisted local heating. Mater. Des. 2016, 90, 364-372. [CrossRef]

28. Salah, A.; Said, A.; Fattah, G.A. Thermo optical switching of paraffin wax hosting carbon fillers. In Proceedings of the 5th World Congress on Materials Science \& Engineering, Alicante, Spain, 13-15 June 2016.

29. Said, A.; Salah, A.; Fattah, G.A. Thermo-optic switching of paraffin-wax hosting either graphite or graphene. Mater. Chem. Phys. 2017, Under Review.

30. Hummers, W.S., Jr.; Offeman, R.E. Preparation of Graphitic Oxide. J. Am. Chem. Soc. 1958, 80, 1339. [CrossRef]

31. Jeon, I.Y.; Choi, H.J.; Bae, S.Y.; Chang, D.W.; Baek, J.B. Wedging graphite into graphene and graphene-like platelets by dendritic macromolecules. J. Mater. Chem. 2011, 21, 7820-7826. [CrossRef]

32. Raoa, Z.H.; Zhanga, G.Q. Thermal Properties of Paraffin Wax-based Composites Containing Graphite. Energy Sources Part Recovery Util. Environ. Eff. 2011, 33, 587-593. [CrossRef]

33. Zhang, Z.; Zhang, N.; Peng, J.; Fang, X.; Gao, X.; Fang, Y. Preparation and thermal energy storage properties of paraffin/expanded graphite composite phase change material. Appl. Energy 2012, 91, 426-431. [CrossRef]

34. Zhang, P.; Song, L.; Lu, H.; Wang, J.; Hu, Y. The influence of expanded graphite on thermal properties for paraffin/high density polyethylene/chlorinated paraffin/antimony trioxide as a flame retardant phase change material. Energy Convers. Manag. 2010, 51, 2733-2737. [CrossRef]

35. Fan, L.W.; Fang, X.; Wang, X.; Zeng, Y.; Xiao, Y.Q.; Yu, Z.T.; Xu, X.; Hu, Y.C.; Cen, K.F. Effects of various carbon nanofillers on the thermal conductivity and energy storage properties of paraffin-based nanocomposite phase change materials. Appl. Energy 2013, 110, 163-172. [CrossRef]

36. Li, J.F.; Lu, W.; Zeng, Y.B.; Luo, Z.P. Simultaneous enhancement of latent heat and thermal conductivity of docosane-based phase change material in the presence of spongy graphene. Sol. Energy Mater. Sol. Cells 2014, 128, 48-51. [CrossRef]

37. Thomas, L.; Aubuchon, S. Heat Capacity Measurements Using Quasi-Isothermal MDSCTM; TA Instruments: New Castle, DE, USA; Available online: http://www.tainstruments.com/pdf/literature/TA230.pdf (accessed on 12 May 2017).

38. Liu, Y.; Yang, H.; Liao, N.; Yang, P. Investigation on thermal conductivity of bilayer graphene nanoribbons. RSC Adv. 2014, 4, 54474-54479. [CrossRef]

39. Cao, Z.; Qiu, F.; Wang, Q.; Cao, G.; Guan, Y.; Zhuang, L.; Xu, X.; Wang, J.; Chen, Q.; Yang, D. Preparation, thermo-optic property and simulation of optical switch based on azo benzothiazole polymer. Appl. Phys. B 2013, 111, 93-102. [CrossRef]

40. Noh, Y.O.; Lee, H.J.; Won, Y.H.; Oh, M.C. Polymer waveguide thermo-optic switches with $-70 \mathrm{~dB}$ optical crosstalk. Opt. Commun. 2006, 258, 18-22. [CrossRef]

41. Han, Y.T.; Shin, J.U.; Park, S.H.; Lee, H.J.; Hwang, W.Y.; Park, H.H.; Baek, Y. N $\times$ N polymer matrix switches using thermo-optic total-internal-reflection switch. Opt. Express 2012, 20, 13284-13295. [CrossRef] [PubMed] 
42. Ye, F.; Qiu, F.; Yang, D.; Cao, G.; Guan, Y.; Zhuang, L. Preparation and thermo-optic switch properties based on chiral azobenzene-containing polyurethane. Opt. Laser Technol. 2013, 49, 56-63. [CrossRef]

43. Yang, J.; Zhou, Q.; Chen, R.T. Polyimide-waveguide-based thermal optical switch using total-internal-reflection effect. Appl. Phys. Lett. 2002, 81, 2947-2949. [CrossRef]

44. Liu, C.; Wang, D.; Yao, L.X.; Li, L.; Wang, Q.H. Electrowetting-actuated optical switch based on total internal reflection. Appl. Opt. 2015, 54, 2672-2676. [CrossRef] [PubMed]

45. Ren, H.; Xu, S.; Liu, Y.; Wu, S.T. Liquid-based infrared optical switch. Appl. Phys. Lett. 2012, 101, 41104. [CrossRef]

46. Sun, P.; Reano, R.M. Submilliwatt thermo-optic switches using free-standing silicon-on-insulator strip waveguides. Opt. Express 2010, 18, 8406-8411. [CrossRef] [PubMed]

(c) 2017 by the authors. Licensee MDPI, Basel, Switzerland. This article is an open access article distributed under the terms and conditions of the Creative Commons Attribution (CC BY) license (http:// creativecommons.org/licenses/by/4.0/). 